\title{
An audit of surgical repair of Tetralogy of Fallot in an African tertiary care centre
}

\section{Deliwe P. Ngwezi", Katharina Vanderdonck", Solomon E. Levin" and Antoinette Cillierst}

\author{
"Stollery Children's Hospital, University of Alberta, Edmonton, \\ Alberta, Canada \\ \#University of the Witwatersrand, Charlotte Maxeke Johannesburg \\ Academic Hospital, Johannesburg, South Africa \\ University of the Witwatersrand, Chris Hani Baragwanath Hospital, \\ Johannesburg, South Africa
}

\section{Address for correspondence: \\ Dr Deliwe P. Ngwezi \\ Stollery Children's Hospital \\ University of Alberta \\ 4C2, 8440-1 12 Street \\ Edmonton \\ Alberta \\ T6G 2B7 \\ Canada}

Email:

ngwezi@ualberta.ca

\section{INTRODUCTION}

Tetralogy of Fallot (TOF) is one of the most common forms of cyanotic congenital heart disease (CHD) with a prevalence of 0.26 per I 000 live births. Significant advances have been made in the surgical repair of this defect with $90 \%$ of patients surviving to adulthood. ${ }^{(1,2)}$ The surgical techniques vary depending on the complexity of the underlying anatomy. The surgical approach can be either a single stage repair or a 2 stage repair. The latter consists of an initial palliative procedure called a Blalock-Taussig (B-T) shunt, central shunt (Potts or Waterston shunt) or placement of a stent in the right ventricular outflow tract (RVOT) in selected cases, followed by a complete repair at a later stage. ${ }^{(2,3)}$

Pulmonary regurgitation (PR), one of the most frequent complications after surgical repair of TOF, was for a long time thought to be well tolerated. ${ }^{(1,3)}$ Over time, evidence has emerged that severe PR post-repair of TOF has detrimental effects on the right ventricle (RV) and it is not the benign lesion it was thought to be. . $^{(4-6)}$ In the early post-operative period, children appear to tolerate severe PR very well. However, it does seem that a prolonged volume over-

\section{ABSTRACT}

Background: For patients undergoing Tetralogy of Fallot (TOF) repair at institutions in sub-Saharan Africa, data on type of surgical repair, operative mortality and important determinants of outcome such as age at operation and development of pulmonary regurgitation (PR) post-repair is scanty.

Objective: To describe the outcomes of children diagnosed with TOF who underwent surgical repair at our center with emphasis on post-operative PR.

Methods:This was a retrospective cohort study undertaken from I January 1994 to 31 December 2003 at Charlotte Maxeke Johannesburg Academic Hospital (CMJAH). The descriptive analysis of the clinical audit was done in 2010. Results: Fifty four (75\%) patients were operated upon: 50 (92.5\%) had complete repair and $4(7.4 \%)$ had a palliative procedure in the form of a Blalock-Taussig (B-T) shunt. The median age for corrective surgery was $\mathbf{3 9 . 5}$ months.

Twenty out of 50 (40\%) patients had simple repair, 10 (20\%) had repair which included pulmonary valvotomy, 15 (30\%) had a transannular patch (TAP) repair with or without monocusp and 5 (10\%) had conduit insertion.

An evaluation of severe PR among all the repair groups in the immediate post-operative period $(<1$ year) revealed that 5 out of 15 (33.3\%) patients who had TAP repair developed severe PR, whilst no severe PR was noted in the simple, pulmonary valvotomy and conduit repair groups. During the intermediate post-operative period ( $\mathrm{I}-5$ years), severe PR was documented in 4 (27\%) patients with TAP repair, $2(10 \%)$ with simple repair and $2(20 \%)$ in the pulmonary valvotomy group only. In the long term period (>5 years), severe PR was documented in 3 (30\%) patients with pulmonary valvotomy, 8 (53\%) who had TAP repair, $2(10 \%)$ patients with simple repair including I (20\%) patient with a xenograft conduit.

One out of $50(2 \%)$ surgically corrected patients who had a complex anatomy died in the immediate post-operative period. Twenty eight out of $50(56 \%)$ patients who had complete correction were lost to follow-up.

Conclusion: Surgical correction occurs much later in infancy and childhood compared to developed countries. Severe PR is a serious complication strongly associated with all types of surgical repair of TOF and these patients require lifelong follow-up. Despite the small sample size, the operative mortality compares favourably to first world centers. SAHeart 2013; 10:520-525 
load on the RV caused by severe PR results in progressive deterioration of myocardial function, arrhythmias and risk of sudden cardiac death. ${ }^{(3,6,8)}$ The volume overload on the RV in turn results in the development of RV dilatation, tricuspid regurgitation (TR) and right atrial enlargement which has been shown to improve with pulmonary valve replacement (PVR)..5,7)

The optimum timing for PVR is not yet certain, especially in asymptomatic patients with severe PR. ${ }^{(5,7)}$ However, the guidelines for PVR in the symptomatic group of patients have been established. (7) Symptomatic patients who undergo a PVR procedure experience a marked improvement in their symptoms. In addition, it has also been noted that RV function assessed by echocardiography $(\mathrm{ECHO})$ improves and cardiomegaly diagnosed on Chest X-Ray (CXR) reduces after treatment of the PR. ${ }^{(7)}$ Right ventricular dysfunction may persist if treatment is delayed and left too late. ${ }^{(5,7)}$

Very little information exists regarding the follow-up of children with TOF post-surgery on the African Continent in the modern day era and how their outcomes compare to other more resource replete institutions in the first world. Therefore, a descriptive retrospective analysis was undertaken to assess the outcomes of children diagnosed with TOF, who were referred to Charlotte Maxeke Johannesburg Academic Hospital (CMJAH) which is a subSaharan tertiary care center for surgical repair of their cardiac defects, with emphasis on the development of post-operative PR.

\section{PATIENTS AND METHODS}

\section{Patients}

A retrospective clinical audit of patient files with a diagnosis of classical TOF at CMJAH who underwent surgery between I January 1994 and 31 December 2003 was undertaken. Classical TOF is described as: subvalvar / valvar / supravalvar pulmonary stenosis (PS) with a ventricular septal defect (VSD), aortic override and right ventricular hypertrophy (RVH). All patients with TOF with absent pulmonary valve syndrome and pulmonary atresia with VSD were excluded.

Ethics approval was obtained from the University of Witwatersrand Ethics Committee.

\section{Methods}

Three categories of data were extracted from each patient file. The first category was demographic data consisting of age at first visit, sex and ethnic group. The second category was operative data with the following descriptions: initial palliative surgery followed by corrective surgery, primary corrective surgery, age at palliation, age at corrective surgery, anatomic findings recorded in the surgical reports, surgical technique used: simple repair, transannular patch (TAP) repair, conduits or pulmonary valvotomy, follow-up and mortality data. The third category of data collected was specific post-operative follow-up details of PR detected on ECHO.

Data on quantification of PR, as determined by colour flow Doppler mapping techniques, was extracted. The pressure half-time variable was not collected because this modality of assessing PR was utilised much later in our institution.

Pulmonary regurgitation was assessed during 3 post-operative time intervals as follows: the immediate post-operative period $(<1$ year); intermediate post-operative period ( 1 - 5 years) and long term period ( $>5$ years)

\section{Definitions}

The measurement of PR by colour flow Doppler refers to the retrograde flow into the RV during diastole. The severity of PR was assessed qualitatively by visualising the extent of the PR jet width into the RV and was then graded as mild, moderate and severe according to the recommendations as set out by the European Society of Cardiology. ${ }^{(8)}$

The local definitions of the various repair techniques are described in Table I and listed below:

- Simple Repair: This technique entails closure of VSD and resection of infundibular muscle bundles with or without RVOT patch only.

- Complex Repair: This is undertaken for more complex anatomy which includes multilevel areas of obstruction in the RVOT usually associated with a hypoplastic pulmonary valve and $z$ score $\leq-2$. The repair includes a TAP repair, with or without inclusion of a monocusp valve, or a conduit insertion using a homograft or xenograft. A pulmonary valvotomy is undertaken if the surgeon is satisfied with the adequacy of the pulmonary valve annulus. A Hegar's dilator is used to assess the size of the pulmonary valve annulus followed by a pulmonary valvotomy in the case of pulmonary valve stenosis. In the majority of the cases, the surgical approach was through a ventriculotomy.

\section{Statistical method}

The data obtained was entered onto an Excel spreadsheet and statistical analysis was done using a statistical software package STATA 10.0. Descriptive statistics of patient demographics were undertaken. Comparisons of groups were made using the Chisquare where applicable. A p-value $<0.05$ was accepted to indicate a significant difference between patient groups. 


\begin{tabular}{|c|c|c|}
\hline Type of repair & $\begin{array}{l}\text { Type of anatomy } \\
(n=50)\end{array}$ & Total number \\
\hline MR+RVOT patch & Simple: Infundibular stenosis only & $20(40 \%)$ \\
\hline $\begin{array}{l}\text { MR+RVOT patch+ } \\
\text { pulmonary valvotomy }\end{array}$ & Complex: PV stenosis & $10(20 \%)$ \\
\hline $\begin{array}{l}\text { MR+RVOT patch+ } \\
\text { TAP }\end{array}$ & Complex: Multilevel stenosis & $7(14 \%)$ \\
\hline $\begin{array}{l}\text { MR+RVOT patch+ } \\
\text { TAP+Monocusp }\end{array}$ & Complex: Multilevel stenosis & $8(16 \%)$ \\
\hline Homograft & Complex: Multilevel stenosis & $2(4 \%)$ \\
\hline Xenograft & Complex: Multilevel stenosis & $3(6 \%)$ \\
\hline
\end{tabular}

$M R=$ muscle resection; $R V O T=$ right ventricular outflow tract; $T A P=$ transannular patch.

\section{RESULTS}

Database search

Figure $I$ is an illustration of the process of patient selection. A total of 54 patient files were suitable for analysis. Fifty four patients (75\%) were operated: 50 (92.5\%) had complete repair and 4 (7.4\%) had a palliative B-T shunt as their only operation. Forty eight patients out of 50 (96\%) underwent a primary repair and 2 (4\%) had an initial B-T shunt prior to complete repair of their defects.

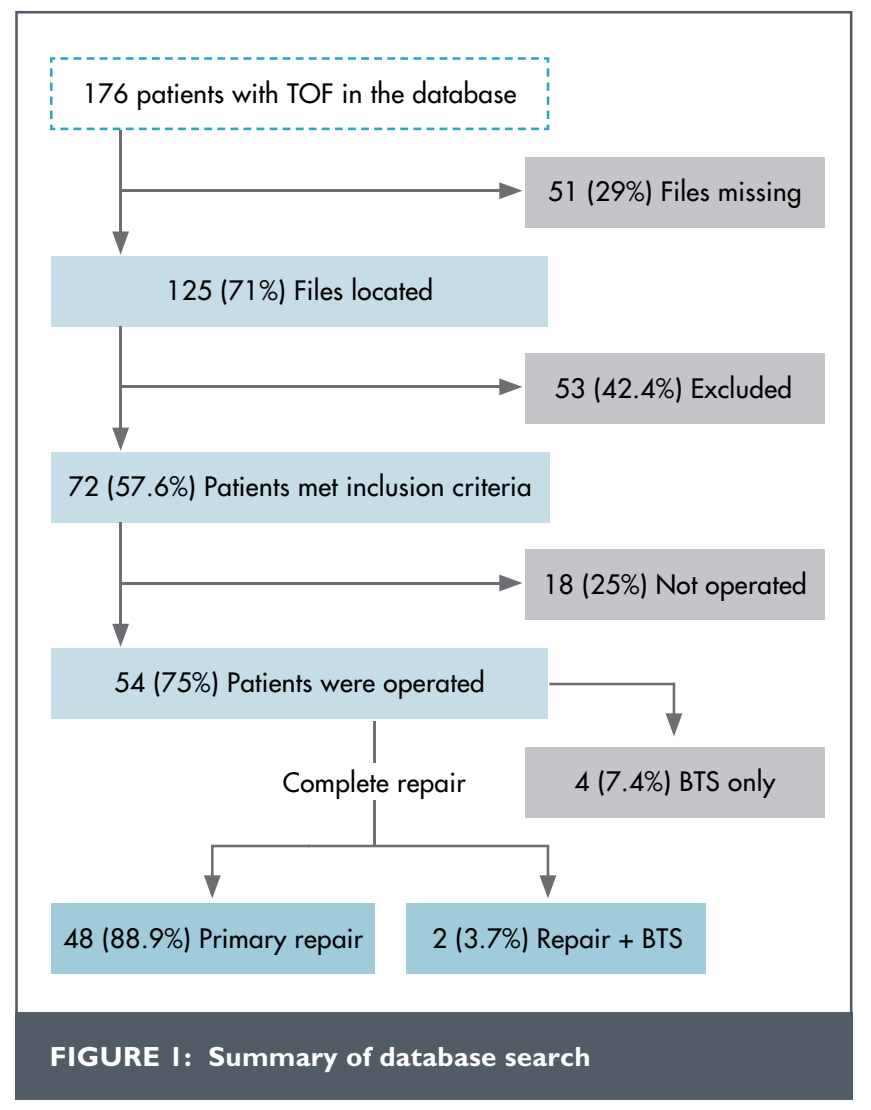

Description of clinical demographics of patients who underwent TOF repair

Twenty nine patients (58\%) were males and 21 (42\%) were females. The median age at surgical repair was 39.5 months (range, 3 - 210 months) as shown in Table 2. There was no statistical difference when comparing the proportions of patients with simple and complex anatomy between male and female patients, $p=0.05$ as shown in Table 3.

\section{Analysis of post-operative severe PR}

Fifteen (30\%) patients had a TAP repair, 20 (40\%) had a simple repair, 10 (20\%) had pulmonary valvotomy and 5 (10\%) had insertion of either a homograft or xenograft conduit as shown in Table I. A summary of the patients who had documented ECHO evaluation of the severity of PR during the three time intervals after operation is shown in Table 4. Severe PR manifested early in the immediate post-operative period $(<1$ year) in 5 (33.3\%) of the TAP repair group but not in the simple, conduit and pulmonary valvotomy repair groups. During the intermediate period

TABLE 2: Demographic data of patients with repaired TOF $n=50$

\begin{tabular}{lc}
\hline Variable & Number $\%$ \\
\hline Male sex & $29(58 \%)$ \\
Race & \\
Black & $37(74 \%)$ \\
White & $5(10 \%)$ \\
Indian & $4(8 \%)$ \\
Coloured & $4(8 \%)$ \\
Repair age groups in months & \\
$0-6$ & $1(2 \%)$ \\
$7-24$ & $15(30 \%)$ \\
$25-48$ & $13(26 \%)$ \\
$49-72$ & $11(22 \%)$ \\
$73-96$ & $5(10 \%)$ \\
$97-120$ & $2(4 \%)$ \\
I2I - 167 & $0(0 \%)$ \\
I68- 250 & $3(6 \%)$ \\
\hline Median repair age & \\
Months & 39.5 \\
Range & $3-210$ \\
IQR range (25 - 75) & $20-68$ \\
\hline
\end{tabular}

TABLE 3: Comparison of simple and complex anatomy

\begin{tabular}{|c|c|c|c|c|c|}
\hline & \multicolumn{2}{|c|}{ Simple anatomy } & \multicolumn{3}{|c|}{ Complex anatomy } \\
\hline & $\mathbf{n}$ & $\%$ & n & $\%$ & $\mathbf{p}^{*}$ \\
\hline Female & 5 & 23.8 & 16 & 76.2 & 005 \\
\hline Male & 15 & 51.7 & 14 & 48.0 & \\
\hline
\end{tabular}

*Level of difference by $x^{2}$ analysis. 
TABLE 4: Comparison of severe PR for the 4 types of repair techniques

\begin{tabular}{|c|c|c|c|c|}
\hline Variable & $\begin{array}{c}\text { TAP repair } \\
(n=15)\end{array}$ & $\begin{array}{l}\text { Simple repair } \\
\qquad(n=20)\end{array}$ & $\begin{array}{c}\text { Valvotomy } \\
(n=10)\end{array}$ & $\begin{array}{c}\text { Conduits } \\
(n=5)\end{array}$ \\
\hline $\begin{array}{c}\text { Severe PR } \\
<\text { | year } \\
\text { post op }\end{array}$ & $5(33.3 \%)$ & $0(0 \%)$ & $0(0 \%)$ & $0(0 \%)$ \\
\hline $\begin{array}{l}\text { I - } 5 \text { years } \\
\text { post op }\end{array}$ & $4(27 \%)$ & $2(10 \%)$ & $2(20 \%)$ & $0(0 \%)$ \\
\hline $\begin{array}{l}>5 \text { years } \\
\text { post op }\end{array}$ & 8 (53\%) & $2(10 \%)$ & $3(30 \%)$ & I (20\%) \\
\hline
\end{tabular}

( I - 5 years), severe PR was documented in 4 (27\%) of the TAP repair patients, 2 (20\%) of pulmonary valvotomy and 2 (10\%) of the simple repair groups. During the long term follow-up period (>5 years), severe PR was found in 8 (53\%) patients who had undergone TAP surgery, 2 (10\%) with simple repair and in 3 (30\%) patients that had had pulmonary valvotomy surgery. One out of 5 (20\%) patients with conduits progressed to severe PR and this is discussed in the section below.

Analysis of subgroup repaired with conduits

A total of 5 out of 30 (16.7\%) patients in the complex anatomy category had conduits inserted at the initial surgery. Two out of 5 (40\%) patients had homografts and 3 (60\%) had xenografts inserted. Post-operative echo data was available for the 2 patients with homografts and only I xenograft recipient. In the immediate post-operative period, both patients with the homograft conduits had mild PS and no PR documented on ECHO. One patient developed moderate PR and remained with mild PS in the intermediate follow-up period. For the long term period, one of the homograft recipient patients progressed to moderate PS and mild PR following calcific degenerative changes that occurred within the homograft conduit and the other patient had no $\mathrm{ECHO}$ data captured during the long term period and is lost to follow-up. The patient with a xenograft developed mild PR and PS during the immediate post-operative period. The degree of PR and PS was both recorded as moderate in the intermediate post-operative period and both PR and PS became severe in the long term period. This patient was eventually lost to follow-up, but was documented to be asymptomatic at the last visit.

\section{Symptomatic patients}

Three out of the 50 (6\%) patients who underwent correction developed symptoms, 2 (66.7\%) of which underwent TAP surgery and I (33.3\%) which had a pulmonary valvotomy. The main symptoms recorded were effort intolerance and chest pain. Two out of the 15 (13.3\%) patients who had previously had a TAP repair, required a PVR 6 to 13 years after the initial surgery. In addition, the patient who was re-operated much earlier after 6 years had a residual right pulmonary artery (RPA) stenosis. One patient who had had a previous pulmonary valvotomy was awaiting a PVR at the time of this audit.

\section{Patient follow-up}

Figure 2 is a flow diagramme depicting the follow-up of patients. A total of 28 out of 50 (56\%) surgically corrected patients were lost to follow-up (LFU), 2 (4\%) patients were transferred to an adult cardiology clinic and 20 (40\%) are still being followed up at the outpatient cardiac clinic.

\section{Peri-Operative Mortality}

One out of 50 (2\%) surgically corrected patients with complex anatomy died during the immediate post-operative period following insertion of a xenograft.

\section{DISCUSSION}

This current study is a documentation of the experience of one centre in the sub-Saharan region which highlights the established knowledge that PR is a frequent complication following repair of TOF. The retrospective nature of the study hindered adequate data collection and therefore did not permit a comprehensive statistical analysis. Nevertheless, sufficient data was obtained to make comparisons with other tertiary centers offering surgical correction to patients with TOF. $(1,6)$ The male predominance in patients with TOF is consistent with previous studies in other parts of the world. $(6,9,10)$

In South Africa and sub-Saharan Africa, many patients present at an advanced stage of their disease, especially amongst the disadvantaged populations who have poor access to proper medical care. Consequently many children with CHD living in poorly resourced

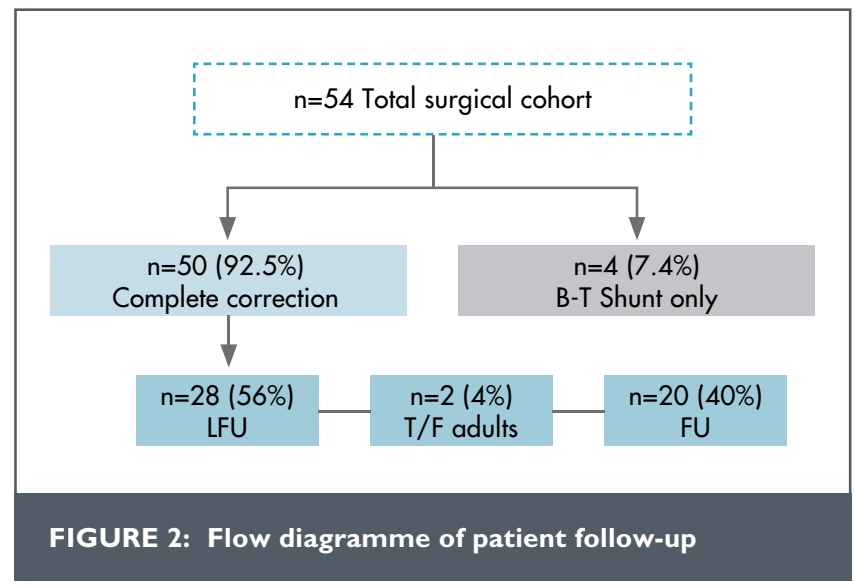

LFU = lost to follow-up; $F U=$ follow-up; $T / F=$ transfer to adults; BTS = Blalock-Taussig Shunt. 
communities are likely to die undiagnosed or lost to follow-up after the diagnosis has been made. In contrast, high income countries report the highest birth prevalence of CHD because of early clinical detection in the antenatal period and during infancy. Such data are unavailable for low income countries because of lack of resources. (I) Likewise, the diagnosis of TOF has evolved remarkably with the majority of cases being detected during fetal life in developed countries.(2) Although there is no consensus regarding the optimum timing for surgical correction, ${ }^{(12)}$ most centers undertake surgical repair of the defect between 3 to 6 months of age. ${ }^{(2)}$ Neonatal surgery is usually reserved for infants with hypercyanotic spells or severe cyanosis. ${ }^{(2)}$ The median age at first presentation in the study cohort was 13 months and the median age at surgical repair was 39.5 months. The youngest patient to have corrective surgery was 3 months old, whilst the oldest was 17 years old. Surgical outcomes compare favourably with the developed world; ${ }^{(2,18)}$ however there is a much earlier detection of patients mainly in the antenatal period in the first world countries. ${ }^{(2)}$

A significant proportion (78\%) of the study patients, as shown in Table 2, underwent primary repair during infancy and early childhood which is thought to be related to the improvement in surgical skills over time resulting in successful post-operative outcomes of younger patients with TOF. ${ }^{(4,13,9)}$ However, similar results in primary repair of TOF in the neonatal period have not been achieved at the same level as other centers with better resources and infrastructure. ${ }^{(13)}$

The majority of patients (60\%) in this study were found to have complex anatomy at the time of operation, similar to other studies, ${ }^{(1,6)}$ requiring various forms of complex repairs that incorporate a TAP, pulmonary valvotomy or conduit insertion. The remaining 40\% underwent simple repairs for less complex TOF anatomy. One study differed in their findings, with the majority of their patients (66\%) undergoing a simple repair and the remainder (31\%) having a complex repair in the form of a TAP. ${ }^{(10)}$ The disparity occurred because the authors in that study included pulmonary valvotomy as part of a simple TOF repair. Furthermore, a comparison of the proportions of patients with simple and complex anatomy between male and female patients revealed no statistical difference, $p=0.05$ as shown in Table 3 .

Pulmonary regurgitation, which is a frequent complication following repair of TOF has recently been shown to be detrimental to the $\mathrm{RV}$, hence the move to earlier PVR in selected cases. ${ }^{(4,5,10,14)}$ The effects of a prolonged volume overload on the RV caused by severe PR results in progressive deterioration of myocardial function, RV dilatation, TR, arrhythmias, effort intolerance and risk of sudden cardiac death. ${ }^{(3,6,8)}$ The most common surgical procedure undertaken during TOF repair which is associated with severe PR is a TAP repair. Eight out of 15 (53\%) patients who had TAP repair, developed severe PR in the long term period as shown in Table 4, two of whom required a PVR. One of these patients required a PVR 6 years after the TAP and also had RPA stenosis. The combination of $P R$ and residual distal stenotic lesions has a more adverse effect on the RV than PR alone, often requiring earlier intervention. In contrast, the second patient with severe PR and no associated stenosis went thirteen years following a TAP repair before needing a PVR, after which his reduced effort tolerance and functional status improved dramatically.

The reduced durability of RVOT prosthesis in 3 out of 5 study patients who had valved conduits inserted during their initial repair was noted. The 2 patients who had homografts inserted, developed a combination of mild to moderate PS and PR over time. Neither of the patients progressed to severe PR. The patient with the xenograft progressed to severe PS and PR in the long term period. Although the overall durability of most RVOT prosthesis is generally limited to 5 - 10 years at the most, ${ }^{(15,16)}$ none of the study patients with valved conduits, including the patients lost to followup, have had re-operation. These patients had a minimum follow-up of I year to 10 years at the most post-surgery.

A surprising finding was the development of severe PR in 2 patients who underwent a simple repair (infundibular muscle resection and RVOT patch) more than 5 years post-surgery. The patients were asymptomatic at the last follow-up visit. A possible mechanism may be an aggressive infundibulectomy resulting in aneurysmal dilatation of the RVOT which is associated with akinetic regions and poor forward flow. ${ }^{(5,7)}$

This study has corroborated the findings of other studies, as mentioned before, that PR and RV dilatation in the immediate postoperative period does increase in severity over time after TAP repair and in some cases following simple repairs. Unfortunately, the development of PR may occur following all types of repair and cannot be avoided altogether. ${ }^{(6)}$

The most plausible explanation for the poor follow-up of the study patients is two-fold. Firstly, it is likely that the patients' symptoms improve after surgery and that they therefore do not feel compelled to return for routine check-ups until problems re-surface. Secondly, it may be that socio-economic conditions hinder compliance with follow-up hospital visits. A study done in China, which is classified as a developing economy similar to South Africa, has similarly attributed poor follow-up in their cohort of patients to financial constraints. $^{(17)}$ 
Overall peri-operative mortality for repair of TOF has declined drastically since the early surgical era from $40 \%$ in $1954,{ }^{(2)}$ to $2 \%$ at the end of the twentieth century. ${ }^{(18)}$ The long term survival rate of 90 - 93\% for patients with repaired TOF closely approximates that of the normal population. ${ }^{(1,2)}$ It is encouraging that the perioperative mortality of $2 \%$ achieved by the study center is comparable to that attained by other first world centers. ${ }^{(18)}$

\section{LIMITATIONS}

The retrospective nature of the study design has affected the strength of the audit. Several factors such as loss to follow-up and absence of crucial echocardiographic data relating to the timing and severity of PR in some patients have possibly reduced the validity of the patient outcomes.

\section{CONCLUSION AND RECOMMENDATIONS}

Despite the study's shortcomings, the findings do support comparable peri-operative mortality to more resource replete centers. In addition, there is confirmation of well-established evidence from first world institutions that severe PR is frequently associated with TAP repair but may also occur in patients undergoing other types of repair. Patients with severe PR require frequent assessments to decide the appropriate timing for PVR.

Features of the study that are not consistent with the developed world are that patients with TOF present much later in infancy and childhood as a result of lack of awareness by care givers and suboptimal detection rate at primary care level. The importance of follow-up of the patients needs to be better communicated to their families and the public at large in order to reduce the high attrition rate post-surgical correction of CHD from continued medical care. The development of medical technology presents an opportunity to follow the progression of patients with severe PR post TOF repair using more advanced $\mathrm{ECHO}$ techniques and cardiac magnetic resonance imaging. These newer modalities may assist decision making regarding a more timely intervention to prevent possible adverse effects of severe PR on the RV.

\section{Conflict of interest: none declared.}

\section{REFERENCES}

I. Murphy JG, Gersh BJ, Mair DD, et al. Long-term outcome in patients undergoing surgical repair of Tetralogy of Fallot. N Engl J Med 1993;329(9):593-9.

2. Apitz C, Webb GD, Redington AN. Tetralogy of Fallot. Lancet 2009; 374(9699): | 462-147|.

3. Lillehei WC, Varco RL, Cohen M, et al. The first open heart corrections of Tetralogy of Fallot: A 26 - 31 year follow-up of 106 patients. Ann Surg 1986; 204:490-502.

4. De Ruijter FTH, Weenink I, Hitchcock FJ, et al. Right ventricular dysfunction and pulmonary valve replacement after repair of Tetralogy of Fallot. Ann Thorac Surg 2002;73: $1794-800$.

5. Bouzas B, Kilner PJ, Gatzoulis MA. Pulmonary regurgitation: not a benign lesion. Eur Heart J 2005;26(5):433-9.

6. Hickey EJ, Veldtman G, Bradley TJ, et al. Late risk of outcomes for adults with repaired Tetralogy of Fallot from an inception cohort spanning four decades. Eur J Cardiothorac Surg 2009;35:156-66.

7. Ammash NM, Dearani JA, Burkhart HM, et al. Pulmonary regurgitation after Tetralogy of Fallot Repair: Clinical features, sequelae, and timing of pulmonary valve replacement. Congenit Heart Dis 2007;2:386-403.

8. Lancelotti P, Tribouilloy C, Hagendorff A, et al. European Association of Echocardiography recommendations for the assessment of valvular regurgitation. Part I: Aortic and pulmonary regurgitation (native valve disease). Eur J Echocardiogr 20 10; 1 1:223-244.

9. Nollert G, Fischlein $T$, Bouterwek $S$, et al. Long-term survival in patients with repair of Tetralogy of Fallot: A 36-year follow-up of 490 survivors of the first year after surgical repair. J Am Coll Cardiol 1997;30:1374-83.

10. Kirklin JK, Kirklin JW, Blackstone EH, et al. Effect of transannular patching on outcome after repair of Tetralogy of Fallot. Ann Thorac Surg 1989;48:783-91.

1।. Van der Linde D, Konings EEM, Slager MA, et al. Birth prevalence of congenital heart disease worldwide: A systematic review and meta-Analysis. J Am Coll Cardiol 2011;58:2241-2247.

12. Pozzi M, Trivedi DB, Kitchiner D, et al. Tetralogy of Fallot: what operation, at which age. Eur J Cardiothorac Surg 2000; 17(6):631-636.

13. Kantorova A, Zbieranek K, Sauer H, et al. Primary early correction of tetralogy of Fallot irrespective of age. Cardiol Young 2008; 18:153-157.

14. Frigiola A, Redington AN, Cullen $\mathrm{S}$, et al. Pulmonary regurgitation is an important determinant of right ventricular contractile dysfunction in patients with surgically repaired Tetralogy of Fallot. Circulation 2004; I I (supp| II):II- I53-II- 157.

15. Turrentine MW, McCarthy RP, Vijay P. Polytetrafluoroethylene monocusp valve technique for right ventricular outflow tract reconstruction. Ann Thorac Surg 2002;74:2202-5

16. Breyman T, Thies W-R, Boethig D, et al. Bovine valved venous xenografts for RVOT reconstruction: Results after 71 implantations. Eur J Cardiothorac Surg 2002;21:703-710.

17. Guo-Wei H, Xiao-Cheng L, Xiang-Rong K, et al. The current strategy of repair of tetralogy of Fallot in children and adults. Cardiol Young 2008; 18:608-6।4.

18. Knott-Craig C], Elkins RC, Lane MM, et al. A 26 year experience with surgical management of Tetralogy of Fallot: Risk analysis for mortality or late reintervention. Ann Thorac Surg 1998;66:506-I I. 